\title{
MONITORING IN EDUCATIONAL DEVELOPMENT PROJECTS: THE DEVELOPMENT OF A MONITORING SYSTEM*
}

\author{
TJEERD PLOMP, HARI HUIJSMAN and ERIC KLUYFHOUT
}

Department of Education, University of Twente, P.O. Box 217, 7500 AE Enschede, The Netherlands

\begin{abstract}
Monitoring in education is usually focused on the monitoring of educational systems at different levels. Monitoring of educational projects receives only recently explicit attention. The paper discusses first the concepts of educational monitoring and evaluation. After that, the experience with developing a monitoring system in an educational development project is described as a case. These experiences, in combination with literature on project monitoring in other contexts, provide a rich source of ideas, lessons learned, and problems to avoid in designing project monitoring.
\end{abstract}

\section{INTRODUCTION}

Most educational development projects want to contribute to an educational change in an educational system, such as increasing student learning by providing textbooks, spreading educational opportunities by providing distance education, or raising the quality of teaching by providing in-service training to teachers. The audiences of educational projects often want to know how far the project is in accomplishing the planned change. Monitoring activities can help project management with keeping the audiences informed about the progress of their project.

In this paper we present a synthesis of our experience in dealing with monitoring issues in educational development projects. First, we introduce some terminology and concepts related to monitoring. Second, we present our own case, the development of a monitoring system for the In-service Mathematics and Science Teaching Improvement Program in Swaziland. Finally, we discuss some issues related to establishing monitoring systems in educational development projects.

\footnotetext{
* Originally presented at the seminar 'Monitoring of Development Projects: Issues and Prospects', organized by the Technology Development Group, University of Twente, and the Management for Development Foundation, Enschede, 7 and 8 September, 1989.
}

\section{CONCEPTS OF MONITORING AND EVALUATION}

\section{Definition of monitoring}

Project management is responsible for managing a project in such a way that project goals will be achieved. Monitoring is the internal project activity of providing feedback to project management on the progress of the project, the problems it is facing, and the efficiency with which it is being implemented (Bamberger and Hewitt, 1986).

Monitoring is a system of activities with three critical components: it requires the regular collection of information, it requires an evaluation of that information, and most importantly, it requires that the evaluation results in an institutional (project) action (Kiesler and Sproull, 1982; cited in Richards, 1988). Usually, monitoring activities are initiated by project management, and stem from specific questions regarding the expected (planned) progress, stated as project criteria or standards. These are the basis for determining what information should be collected, as well as for making a judgement about the status of the project or the rate of change which is initiated by the project. Depending on the outcome of this evaluation, project management will decide upon actions to be taken, and/or will adjust the expected progress. Figure 1 illustrates the elements of monitoring.

Other authors, like Casley and Kumar (1987), Hopkins (1985), and Posavac and Carey (1989) have similar definitions of monitoring. 


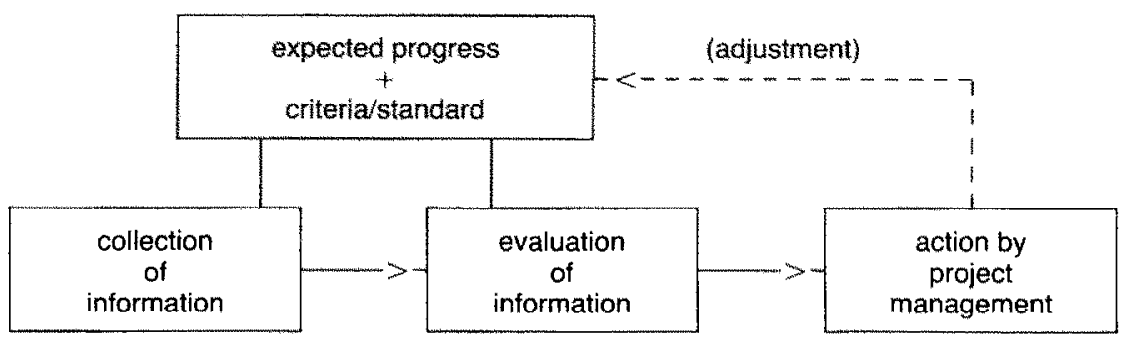

Fig. 1. Elements of monitoring.

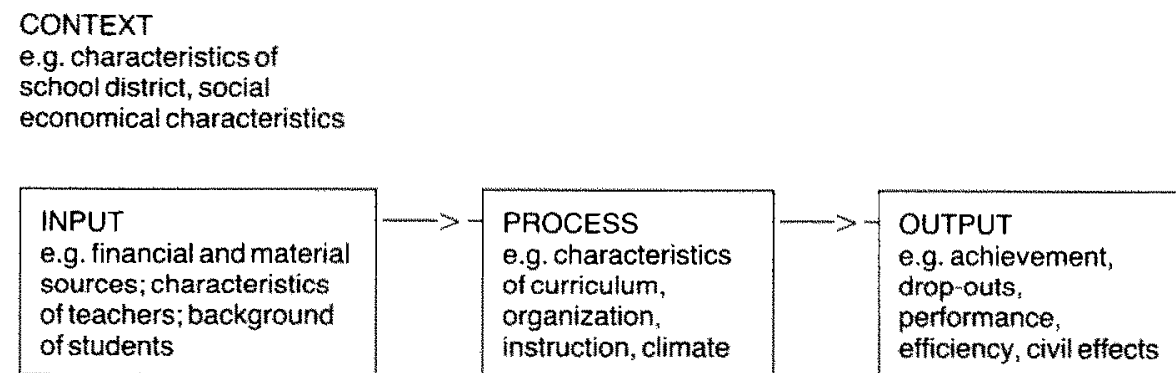

PROCESS

e.g. characteristics of curriculum, organization, instruction, climate

\section{OUTPUT}

e.g. achievement, drop outs. pertormance, efficiency, civil effects

Fig. 2. Model of an educational system (Scheerens et $a{ }_{r,}, 1988$ ).

Typically a systems approach is underlying monitoring. Monitoring itself is being considered as a system, namely the whole of information collection procedures and instruments, system of information storage and retrieval, and procedures of reporting and evaluation of the information. But also the entity which is being monitored is considered to be a system with a context, input, process and output model; see Fig. 2 for an example of an educational system (from Scheerens $e t$ al., 1988).

\section{Types of monitoring}

Monitoring can be directed to project inputs, processes and outputs. The assessment of human and physical resources in a project, and whether they are expended as planned, is called input monitoring. It is to ensure that a project is operating at some predetermined standard, or in other words, that a project is operating as stated in its plan of operation. Input monitoring is mostly directed to the input of a project in the educational system. Examples of input moni- toring are the administration of the distribution of textbooks to schools, or an account of the delivery of in-service workshops to teachers.

Process monitoring is directed to the processes in which a project is involved, in order to assure that these processes are indeed contributing to the expected output. Examples of process monitoring are the assessment of whether distributed textbooks are being used in schools, or the investigation of whether lecturers are participating in in-service training as was planned.

Assessment of whether the project achieves the planned change in the educational system is called performance monitoring. Examples of performance monitoring are a study of whether students have mastered the content of the textbooks, or a report on whether the teachers have changed their teaching strategies.

\section{Locus of authority}

Richards (1988) points to the relevance of the locus of authority of a monitoring system, and related to this, he points to whether project staff 
are intrinsically or extrinsically motivated towards monitoring.

When project staff are interested in selfimprovement, they may be intrinsically motivated to collect information for this purpose. Extrinsically motivated monitoring systems may fit in the model of project inspection, but they can also be the result of the 'intrinsical' motivation of national, state or regional governments to participate in the monitoring of the quality of education at macro level (see for example, OECD's study of educational indicators (Bottani and Delfau, 1990). Monitoring systems initiated at the macro-level may therefore create a conflict with the meso-level if the monitoring system at the macro level is focused at organizational inputs and outputs, while much of the monitoring at the project level-especially when it is initiated by the professional staff of the project - is directed at optimizing internal processes.

\section{Evaluation vs monitoring}

We conceive monitoring as an internal project activity. Project evaluation is an examination of the impact of a project and of the fulfillment of its ultimate objectives, and provides an indication of the reasons for unusually high or low performances (Mickelwait, 1979). Project evaluation can benefit considerably from the information collected by monitoring activities. Internal project evaluation comes close to monitoring, but it differs from it in the sense that it is often a one time activity and does not have a system for regular data collection. Project management can of course decide to do an internal project evaluation based on the information collected by the monitoring system.

\section{CASE: THE IMSTIP MONITORING SYSTEM}

\section{The IMSTIP project}

The In-service Mathematics and Science Teaching Improvement Program (IMSTIP) is a cooperation between the Free University of Amsterdam (FUA), the Ministry of Education in Swaziland (MoE), and the University of Swaziland (UNISWA). The following project goals are stated in project documents:

1. To advise serving teachers on a variety of more effective methods of instruction in the classroom, and of handling laboratory practicals and on simple techniques of improvising some of the requisite equipment;

2. Improved backstopping for teachers as a consequence of improved inspection of schools, which in its turn should bc a result of keeping in close contact both with the schools and the MoE;

3. Improved professional performance in the teaching force.

These goals are summarized by a hope that IMSTIP will play a major role in the overall effort to stimulate and sustain self-confidence and high professional standards among the teachers of mathematics and science.

The activities to reach these goals are:

1. Assist teachers in laboratory management and in the use of mathematics teaching aids;

2. Allow the project team, the Inspectorate and the teachers to put together an acceptable laboratory manual for different science subjects and to produce teaching aids in mathematics teaching;

3. Assist those teachers whose schools have minimal facilities to improvise in order to offer a reasonable level of instruction and, if necessary, to loan equipment from project's stock;

4. Refer to the Ministry of Education, through the Inspectorate, observed needs for better facilities, teaching aids, etc.;

5. Bring to the attention of the university Faculty of Education, under whose auspices the program will be run, areas of difficulty encountered in schools so that their preservice teacher training program can realistically prepare candidates for the actual school situation.

IMSTIP started in August 1985 as a pilot project with 16 high schools, and has been in full operation since August 1986 with all 50 high schools in Swaziland. IMSTIP should be phased out in December 1990 (but plans are being developed to start a follow-up project). The Faculty of Education of UNISWA has the responsibility for the planning and implementation of the project.

The project staff consisted of two full-time staff, six staff during eight months of the year (all subject experts), and a secretary, IMSTIP activities were: organizing workshops and seminars for science and math teachers, and visiting science teachers in their schools. Science workshops (three days), science semi- 


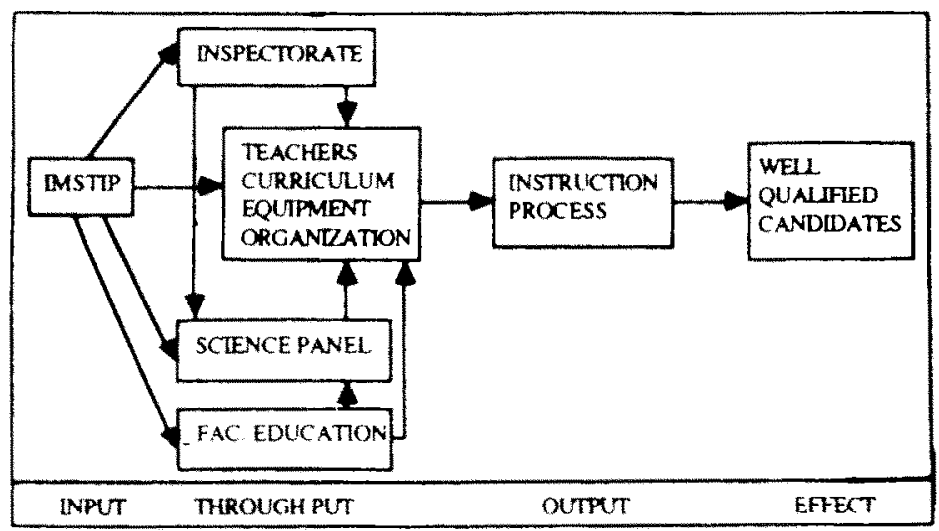

Fig. 3. Conceptual diagram of IMSTIP.

nars (one day), and maths seminars (one day) were organized three times a year.

\section{The IMSTIP monitoring system}

The idea of improving the original monitoring system of IMSTIP was put forward by Huijsman and Kluyfhout (1988). They made a conceptual diagram of the IMSTIP project, in order to visualize and clarify the relation between input, output, and effects. Figure 3 shows this conceptual diagram. The project delivers inputs to schools (assisting teachers, improving the curriculum, supplying equipment, and proposing changes in the organization) and to other organizations which have an interest in improving the instruction process (the Inspectorate, the Science Panel, and the Faculty of Education of the University of Swaziland). Changes in this educational environment (the throughput) are expected to lead to an improved instruction process. Better instruction should result in high school graduates who are qualified to pursue a study in science at the University of Swaziland.

Originally, project staff wrote descriptive 'school reports' whenever they visited a school. These school visit reports were filed in the school's portfolio, and were used when the next school visit had to be prepared. This system of descriptive reports can be considered as a process monitoring system.

The analysis of the school visit reports, resulted in the following recommendations for improving the monitoring system:

1. Collect more data for the benefit of developing long term strategies.

2. Standardize the information which is collected during school visits, so that it becomes less person dependent.

3. Collect data on schools indicating if problems with science education have to do with lab problems, equipment problems, teacher problems or classroom problems.

4. Standardize the processing of data, to make the information gathered and problems encountered more accessible to other staff members.

5. Clarify existing ideas within the project on objectives, values, and criteria on which decisions have to be taken, and maybe develop some scenarios to give long term strategies.

6. Make information on the activities of the project accessible to people not involved in the daily running of the project, such as Steering Committee, donor agencies, etc. (Huijsman and Kluyfhout, 1988).

The project decided that the improved way of monitoring should concentrate on the school variables (teachers, curriculum, equipment and organization), see Fig. 3. Later on, the project wanted to add teacher attendance of workshops and seminars, and the Cambridge Overseas School Certificate (COSC) examination results of the schools to the monitoring system.

The improved way of monitoring provides two types of information on Swazi high schools 
and IMSTIP activities:

1. General information on maths and science education (mostly quantitative), described on the following categories of variables: school personnel, organization, curriculum, available facilities, school results (achievement), use of IMSTIP materials, and the use of laboratories;

2. Specific information on problems with science teaching, mostly qualitative.

Both types of information were collected by IMSTIP staff during school visits. The general information was collected by checking a preprinted mapping form of the school, containing data on school staff, science and mathematics curriculum, science facilities, science equipment, and science fees. Specific information on actual or expected problems with science teaching was collected during an interview with the teacher and recorded on a problem form. The help promised by IMSTIP, as well as what the teacher would do about the problems were also recorded on the problem form.

A database system on a microcomputer was developed, to store and process the data collected via the mapping forms and the problem forms. The data entry was guided by menus and supported by screens, which looked like the data collection forms. The processing of data, resulting in reports/overviews, was also menu-driven. The system helped the user in making overviews of, for example, all general information per school; all pending (still not solved) problems per school; all problems per school (solved as well as unsolved) over a time interval to be specified by the user; all problems per subject area, over all the schools over a time interval to be specified by the user; all pending problems per IMSTIP staff nember; all problems within a certain category (six categories of main problems were defined); all pending problems that needed to be reported to the Inspectorate.

The system was developed between October 1986 and May 1987 by Huijsman and Kluyfhout (1988), as their graduate project for the Department of Education of the University of Twente. The system was developed part by part with involvement of project staff. As soon as a part was finished it was tried-out, demonstrated to the project staff and put into operation. Revisions were made, based on comments of the project staff. This cooperative development process took much longer than planned. Most attention was given to the development of the data collection and the data processing parts, and only limited attention could be given to the evaluation/decision making part (see Fig. 1).

However, the reports produced by the system are structured in such a way that they direct the attention to problems and irregularities. For example, the COSC examination results were printed in different categories, from poor performing schools to high performing schools. With such an overview, the project can easily determine which schools need help and which schools don't need any support. By making these overviews every year, the IMSTEP system could report how well (or poorly) schools are performing over a series of years.

To facilitate systems maintenance, a course on the use of computers and on dBase III Plus (the system's database management language) was provided for the project staff. This course was needed because only two staff members were familiar with the use of computers and no one was familiar with database management software.

\section{Evaluation of the IMSTIP monitoring system}

Given the time constraints only a limited evaluation of the monitoring system was conducted, consisting of activities such as: comparing design features with the original design specifications, comparing the new and the old school reports on quantity and quality of relevant data, and consulting about the system. with project staff and users of information. It was found that:

1. The mapping and problem forms improve the quality and quantity of information about the schools; they make the procedure of data collection easier and more systematic;

2. It is easier to extract relevant information to prepare for school visits;

3. Relevant information is available to the Inspectorate in such a way, that the Inspectorate can inform the Ministry of Education about problems with and shortage of staff, equipment, and facilities;

4. An overview of project activities is available for accountability purposes.

Comments of experts from the UNISWA and FUA were primarily related to the choices made in the stage of system specification:

1. The monitoring system does not look at the results of IMSTIP at the classroom level; as a 
result some people prefer to speak of an internal accounting system, rather than of a monitoring system;

2. Having the focus of the system on the school level and the Inspectorate rather than on the classroom level, may have as a consequence that less activities will be directed at the classroom level;

3. The system gives a one-sided picture of the IMSTIP activities by not collecting enough information on the workshops and seminars. Also some implementation problems were mentioned. Not all project staff supported the use of the new system. One of the major complaints was that it took too much time to maintain the database system, especially at the beginning of the school year when many school visits took place.

External evaluators of the IMSTIP project concluded that 'the system itself is inherently too cumbersome and complex for use in practice, and not all the subroutines incorporated work as they should. In discussions with team members we are not surprised to find that they have been unable to use the facility. In the long term, a more simple database system would be desirable, but the problems of continuously monitoring change in so many schools should not be allowed to adversely affect the rest of the work of the project' (from evaluation report IMSTIP/SPEC, 1989).

\section{Discussion of results}

As social scientists, we believe that accurate information is better than impressionistic information of unknown accuracy. Most of the project staff in our case will agree with this view. But this does not mean that all staff support monitoring activities. Most staff members dislike having their work compared to that of others. lalking about criteria for project success is threatening, especially when the project staff is task-oriented instead of progress-oriented; 'to get the job done' is the primary interest of the project manager. Therefore, input monitoring seems easier to implement than process monitoring or performance monitoring.

The failure of the IMSTIP monitoring system is attributed to the complexity of the database system. This problem can be solved in principle by attracting staff who are capable of maintaining databases. Collecting information by using the mapping form and the problem form is indeed somewhat cumbersome, especially when staff members are used to "just paying a visit' to a school, and have not yet experienced the benefits of using the information collected.

The case described above illustrates that developing a monitoring system is a difficult process, not only from the perspective of 'systems development', but also from the perspective of introducing a change in already established educational projects. In the last part of this paper we will relate our experience to the experiences from developing monitoring systems in other contexts.

\section{DISCUSSION ON MONITORING IN EDUCATIONAL DEVELOPMENT PROJECTS}

\section{Plans and practice do not always match}

Theoretically, a project can only be monitored if certain conditions are fulfilled. Hopkins (1985) mentions four conditions which should be fulfilled before one should consider evaluation activities. These are:

1. Clearly articulated program;

2. Clearly specified goals or effects;

3. Plausible rationale linking the program to the goals or effects (its theoretical basis).

4. Implementation of the actual project.

Also Rondinelli (1983) states that exactly these aspects are usually missing in development projects. In many development projects the project plans are formulated so generally, that all agencies involved in the project agree with it ('consensus building'). It may therefore be difficult to derive concrete monitoring goals from many project proposals.

Additionally, many educational projects are based on 'loyalty': education in developing countries has to be improved, which leads to general goal statements and a lack of concretely specified project output, which often do not allow for rational decision making. But in cases where the project proposal is not specific enough, it must be possible in the early stages of a project to specify concrete variables on which changes are being expected. At this stage, the discussion on how project progress will become measurable, not only helps project management in focusing project monitoring activities. but also contributes to focusing activities. 


\section{Cultural aspects}

Monitoring activities are often asked for by donor agencies or more generally by proper authorities, for example to serve as a basis for the evaluation of a project. The relevance of the type of information which is asked for is often not recognized either by the counterpart or by the project staff. In the case that monitoring systems are extrinsically motivated (e.g. by a donor agency), indigenous people who have to provide information for it, may not see the relevance for this, because they are, for example, not used to the 'rationalism' behind the decision making processes of the donor agencies or the proper authorities.

Similar arguments may apply for project staff: asking for standardized information implies that certain reporting rules have to be followed. Despite the fact that a project is already defined, each group involved, depending on its role and its degree of liberty, will enhance some goals and objectives of the project, adjust some of them to suit their prevailing perception, values and beliefs, or simply ignore part of them (Vanasse, 1985). Also Rondinelli (1983) points to the problem of weak incentives or controls for guiding the behavior of participants in project implementation.

A monitoring system consists of procedures for collecting, storing and reporting information which are more or less standardized. This assumes that communication within a project is based on a common language. Owens and Martin (1985) state that $10 \%$ of the problems experienced by project managers in the international arena have been attributed to the language barrier. The very nature of language itself creates communication obstacles, because many words are imprecise, have different meanings, and result in misinterpretation.

The collection of information in an organizational context can be a sensitive matter and perceived as threatening by many, depending on the characteristics of the organization and the nature of its internal relations. A primary principle of organizational behavior is that one of the best and most effective ways to control the organization is to control the access to information and its flow within the organization. When the collection of information is perceived - correctly or incorrectly, no matter - as being contradictory to one's interests there is a great chance that the processes of information collection will become difficult, complex and subject to inaccuracies. This means that monitoring activities have to take into account the internal culture and politics of the organizational setting in which they are functioning.

\section{Implementation problems}

The IMSTIP monitoring system clearly shows that the introduction of such a system means quite a change for the functioning of the project. An important condition therefore is, that such a system is easy to use (which was apparently not the case with the IMSTIP system).

Another point for consideration is that the project staff should be ready and prepared for using such a system. The IMSTIP project staff did not express a clear demand for an improved monitoring system. As a consequence, the project staff did not develop a sense of 'ownership' with respect to the monitoring system and was not committed to maintain the system.

All these events led to a system, which was not fully incorporated in the project organization. These findings are supported by findings in other educational development projects (Fullan, 1982), and in the field of computer systems development in general and that of management information systems specifically (Gnovent and Ledener, 1988).

It should be stressed that the same implementation problems occur in developed countries as well. The lesson which can be learned from this is that the introduction of monitoring as such, and in particular computer based monitoring, should be approached as a change process, for which a careful implementation strategy needs to be developed (see, e.g. Fullan, 1982).

\section{Process vs performance monitoring}

Process monitoring is focused on the quality of the process in relation to the planned output. In performance monitoring the orientation is at the quality of the output in relation to the needs or demands of the environment. The process can be appropriate given the stated project goals, but these goals may not be sufficiently relevant to meet the environment's demand. Two kinds of activities seem to be required to prepare a useful monitoring system. First, an analysis to find possible discrepancies between an 'actual' and 'desired' situation, leading to 
the operationalization of project goals; this becomes the basis for performance monitoring. Secondly, the analysis of project goals to establish useful means-end relationships. The project processes derived from this form the basis for process monitoring.

\section{Monitoring long term goals}

A project has its own position in attaining certain goals in the long term. In IMSTIP, for example, the goals are summarized in that it is hoped that IMSTIP will contribute to a broad and general goal, namely, playing a major role in the overall effort to stimulate and sustain selfconfidence and high professional standards among the teachers of mathematics and science in Swaziland. The direct project activities are aimed at improving science laboratories in the schools, the science teachers' competence in using these labs, and the competence of mathematics teachers to use teaching aids. Ultimately these activities must result in better achievement of students. These long term goals have to be visible in, and to some extent be part of, the project plan. An important monitoring goal might be to investigate whether the 'short term means' of a project are not only serving the short term project goals, but also contributing to the long term goals, or whether other activities might be more appropriate. In the case of IMSTEP, it is possible that, to realize the long term goals not only laboratory work in schools needs to be improved, but for example teachers' motivation also has to be increased, or the quality of other instructional materials (to which the regular workshops and seminars can be instrumental). So project monitoring needs also to serve long term goals, and may contribute to the planning of a useful sequence of projects.

\section{Monitoring across projects}

Monitoring across similar types of projects could help to develop better theoretical frames of reference for certain types of educational development projects. For monitoring across projects, it is in any case necessary to have well defined projects outputs, because one can only decide to adjust project processes if one knows whether project outputs are not optimal. We already indicated that in many proposals outputs are only vaguely defined.

\section{CONCLUSIONS}

The introduction of a monitoring system in a project can be conceived as an innovative organizational change with certain conditions. Educational projects need to clarify what change in the educational system they are aiming at, and in which way the project is expected to contribute to that change. Project management should feel the need to 'rationalize' their decision making process, and should become interested in the progress of the project. It should commit itself to monitoring activities, by allocating resources for monitoring system development, implementation and maintenance. When any of these conditions are not fulfilled, it will be wise not to consider process or performance monitoring.

When monitoring is regarded as supportive for project management and when project management has agreed upon what to measure, the development of a monitoring system could be considered. Project management should participate in all phases of this development process: planning, developing, implementing, utilizing, and maintaining a monitoring system. Designers must have a 'change' perspective and must take into account the internal culture and politics of the organizational setting in which the monitoring system has to function. It is wise to keep the system as small as possible and directly related to the information needs of project management.

Acknowledgemen - We would like to express great appreciation to Professor Nel Velthorst (Free University Amsterdam) for her helpful comments.

\section{REFERENCES}

Bamberger, M, and Hewitt, E. (1986) Monttoring and Evaluating Urban Development Programs: A Handbook for Program Managers and Researchers (Technical Paper No. 53). World Bank, Washington DC.

Bottani, N. and Delfau, I. (1990) Indicators of the quality of educational systems: an international perspective. International Journal of Educational Research 14.

Casley, D. J. and Kumar, K. (1987) Project Monitoring and Evaluation in Agriculture. The Johns Hopkin University Press, Baltimore, Maryland.

Clark, R. and Freund. P. (eds) (1985) Guidelines on Project Evaluation in Zambia. University of Zambia, Lusaka.

Fullan, M. (1982) The Meaning of Educational Change. Teachers College Press. Columbia University. New York. 
Grover, V. and Lederer, A. L. (1988) Recognizing the politics of MIS. Informatics and Management 14, 145156.

Hopkins, T. J. (1985) Methods and models of evaluation. In Guidelines on Project Evaluation in Zambia (edited by Clark, R. and Freund, P.), pp. 1-23. University of Zambia, Lusaka.

Huijsman, H. Z. C. and Kluyfhout, E. (1988) Monitoring, evaluation, and management information: systems in education development projects. M.Sc. thesis, Dept of Education, University of Twente, Enschede.

Kiesler and Sproull (1982) Managerial responses to changing environments: perspectives on problem sensing from social cognition. Administrative Science Quarterly $27,548-570$.

Mickelwait, D. R. (1979) Information strategies for implementing rural development. In International Development Administration: Implementation Analysis for Development Projects (edited by Honadle, G. and Klauss, R.). Preager Publishers, New York.

Owens, D. S. and Martin, D. M. (1985) Project management and behavioral research in an international context. In Project Management-INTERNET 85 (edited by Vriethoff, W. and Visser, J.), pp. 96-103. Elsevier, Amsterdam.

Posavac, E. J. and Carey, R. G. (1989) Program Evaluation: Methods and Case Studies (3rd ed.). Prentice Hall, Englewood Cliffs, New Jersey.

Richards, C. E. (1988) A typology of educational monitoring systems. Educational Evaluation and Policy Analysis 10(2), 106-116.

Rondinelli, P. A. (1983) Development Projects as Policy Experiments: An Adaptive Approach to Development Administration. Methuen, London.

Scheerens, J., Stoel, W. G. R., Vermeulen, C. J. A. J. and Pelgrum, W. J. (1988) De haalbaarheid van een onderwijsindicatorenstelsel voor het basis- en voortgezet onderwijs. (The feasibility of a system of educational indicators for elementary and secondary education.) Center for Applied Educational Research, OCTO, University of Twente, Enschede.

Vanasse, J. R. (1985) Culture and project management. In Project Management-INTERNET 85 (edited by Vriethoff, W, and Visser, J.), pp. 96-103. Elsevier, Amsterdam, 